\title{
Increased Susceptibility of Striatal Mitochondria to Calcium-Induced Permeability Transition
}

\author{
Nickolay Brustovetsky, ${ }^{1}$ Tatiana Brustovetsky, ${ }^{1}$ Kevin J. Purl, ${ }^{1}$ Michela Capano, ${ }^{2}$ Martin Crompton, ${ }^{2}$ and \\ Janet M. Dubinsky ${ }^{1}$ \\ ${ }^{1}$ Department of Neuroscience, University of Minnesota, Minneapolis, Minnesota 55455, and ${ }^{2}$ Department of Biochemistry and Molecular Biology, \\ University College London, London, WC1E6BT United Kingdom
}

\begin{abstract}
Mitochondria were simultaneously isolated from striatum and cortex of adult rats and compared in functional assays for their sensitivity to calcium activation of the permeability transition. Striatal mitochondria showed an increased dose-dependent sensitivity to $\mathrm{Ca}^{2+}$ compared with cortical mitochondria, as measured by mitochondrial depolarization, swelling, $\mathrm{Ca}^{2+}$ uptake, reactive oxygen species production, and respiration. Ratios of ATP to ADP were lower in striatal mitochondria exposed to calcium despite equal amounts of ADP and ATP under respiring and nonrespiring conditions. The $\mathrm{Ca}^{2+}$-induced changes were inhibited by cyclosporin A or ADP. These responses are consistent with $\mathrm{Ca}^{2+}$ activation of both low and high permeability pathways constituting the mitochondrial permeability transition. In addition to the striatal supersensitivity to induction of the permeability transition, cyclosporin A inhibition was less potent in striatal mitochondria. Immunoblots indicated that striatal mitochondria contained more cyclophilin D than cortical mitochondria. Thus striatal mitochondria may be selectively vulnerable to the permeability transition. Subsequent mitochondrial dysfunction could contribute to the initial toxicity of striatal neurons in Huntington's disease.
\end{abstract}

Key words: permeability transition; brain mitochondria; Huntington's disease; neurotoxicity; regional differences; cyclophilin D

\section{Introduction}

Energetic defects are associated with the pathophysiology of Huntington's disease (HD). Abnormalities in complex II-III activity have been documented in postmortem brains of affected individuals (Browne et al., 1997). Inhibition of succinate dehydrogenase by long exposures to low doses of complex II inhibitors mimics the symptoms and pathology of the disease in both baboons and rodents (Beal et al., 1993). Energetic supplementation via dietary intake of creatine or coenzyme Q extends life spans and improves motor performance in genetically altered mouse models of HD (Andreassen et al., 2001; Schilling et al., 2001; Ferrante et al., 2002). In a Huntington mouse model with a very slow disease progression, subtle changes in mitochondrial enzymes have been noted early in disease progression (Browne et al., 1999). CNS mitochondria from more severe mouse HD models depolarized in response to lower doses of respiratory inhibitors or $\mathrm{Ca}^{2+}$ than those from controls (Sawa et al., 1999; Panov et al., 2002). Thus mitochondrial dysfunction may contribute to the progressive neurological decline in HD.

A number of factors have been compared regionally in searching for the cause of the selective vulnerability of striatal neurons in Huntington's disease. Striatal tissue may be more at risk for both excitotoxic and oxidative damage because of the high density of glutamatergic and dopaminergic nerve terminals (Petersen et al., 2001). Striatal neurons may be more sensitive to NMDA receptor-initiated $\mathrm{Ca}^{2+}$ increases after metabolic inhibition

Received Jan. 13, 2003; revised March 24, 2003; accepted March 26, 2003.

This work was funded by National Institute of Neurological Disorders and Stroke Grant NS 39414 to J.M.D., by American Heart Association Grant $0130497 Z$ to N.B., and by British Heart Foundation Grant 200009 to M.C. Bruce Lindgren and Nicoll Wyman are gratefully acknowledged for their statistical consultation.

Correspondence should be addressed to Janet M. Dubinsky, Department of Neuroscience, University of Minnesota, 6-145 Jackson Hall, 321 Church Street SE, Minneapolis, MN, 55455. E-mail: dubin001@tc.umn.edu. Copyright $\odot 2003$ Society for Neuroscience $\quad$ 0270-6474/03/234858-10\$15.00/0
(Greene et al., 1998). The mutant polyglutamine expansion itself may be more unstable in aged striatal tissue, increasing in length and exacerbating consequences compared with cortex (Kennedy and Shelbourne, 2000). Differential distribution of excitoxicityrelated proteins such as glutamate receptors could also exacerbate local damage (Calabresi et al., 1999, 2001). None of these reported differences, however, can link the energetic abnormalities to the striatal selectivity.

Induction of the mitochondrial permeability transition (mPT) can contribute to mitochondrial dysfunction and subsequent cellular demise in both apoptotic and necrotic injury. The mPT occurs during activation of permeability pathways in the inner mitochondrial membrane in response to $\mathrm{Ca}^{2+}$ and oxidative stress, leading to loss of mitochondrial membrane potential $(\Delta \psi)$ and swelling (Crompton, 1999). In neurons this could be a consequence of an excessive activation of glutamate receptors and prolonged elevation of cytosolic calcium (Dubinsky and Levi, 1998; Nicholls and Budd, 1998). Induction of the mPT may result in cytochrome $c$ release signaling subsequent apoptosis (Brustovetsky et al., 2002), loss of ATP production leading to necrosis, or both (Nicotera et al., 1997, 1998). In a limited substrate environment, opening of a low permeability pathway leads to mitochondrial depolarization without prominent swelling, preventing $\mathrm{Ca}^{2+}$ uptake (Brustovetsky and Dubinsky, 2000). The low permeability pathway may precede induction of a classical high permeability pathway, allowing other cytosolic $\mathrm{Ca}^{2+}$ activated processes to proceed unregulated. We posited that part of the striatal vulnerability may be an increased susceptibility of striatal mitochondria to induction of these permeability pathways by calcium. Therefore we compared purified striatal and cortical mitochondria, isolated simultaneously from the same adult rat brains, in functional mitochondrial assays. 


\section{Materials and Methods}

Mitochondrial isolation. Nonsynaptosomal mitochondria from cortex or striatum were prepared simultaneously from the same brains according to procedure B of Sims (1990). For each experiment, five to six male or female, or both, adult rats (250 gm) were killed following Institutional Animal Care and Use Committee approved protocols. Animals were allowed ad libitum access to food and water before they were killed. Briefly, tissue from each region was homogenized in the isolation medium containing 410 mм sucrose, 0.1 mм EGTA, 10 mм HEPES, pH 7.4, in a Dounce homogenizer and immediately layered on a discontinuous Percoll gradient (Sims, 1990; Brustovetsky and Dubinsky, 2000). This concentration of sucrose was empirically found to produce the highest yield of both cortical and striatal mitochondria. After centrifugation at $31,000 \times g$ for $35 \mathrm{~min}$, all material at the 26 and $40 \%$ Percoll interface was collected and washed twice more in successive centrifugations. The final pellet was resuspended in the isolation medium to equal protein concentrations and stored on ice until use. Mitochondrial protein was determined by the Bradford method (Bradford, 1976) using bovine serum albumin as a standard.

Mitochondrial membrane potential, swelling, $\mathrm{Ca}^{2+}$ uptake, and respiration. Mitochondrial membrane potential and light scattering were measured simultaneously, and $\mathrm{Ca}^{2+}$ uptake and respiration were measured individually in isolated CNS mitochondria at $37^{\circ} \mathrm{C}$ in a continuously stirred, $0.3 \mathrm{ml}$ chamber containing $0.15-0.2 \mathrm{mg}$ protein $/ \mathrm{ml}$. Incubation medium consisted of $125 \mathrm{mM} \mathrm{KCl}, 3 \mathrm{~mm} \mathrm{KH} \mathrm{PO}_{4}, 0.5 \mathrm{mM} \mathrm{MgCl}_{2}, 0.1 \%$ BSA (fatty acid free), $10 \mathrm{~mm}$ HEPES, $\mathrm{pH}$ 7.4. Succinate and glutamate (3 mM each) were present as substrates unless indicated otherwise. In the experiments of Figure 2, $215 \mathrm{~mm}$ sucrose and $50 \mathrm{~mm}$ mannitol were substituted for the $\mathrm{KCl}$. In the experiment of Figure 10, $0.08 \mathrm{mg}$ mitochondrial protein/ml was incubated in $150 \mathrm{~mm} \mathrm{KCl,} 20 \mathrm{~mm}$ MOPS, 10 mм Tris, pH 7.0, 2 mм NTA, $0.5 \mu \mathrm{M}$ rotenone, $0.5 \mu \mathrm{M}$ antimycin A, 3.3 $\mu \mathrm{M} \mathrm{A} 23187$ at $26^{\circ} \mathrm{C}$ (Friberg et al., 1999).

$\Delta \psi$ was followed by monitoring the distribution of tetraphenylphosphonium cation $\left(\mathrm{TPP}^{+}\right.$) between the external medium (initially $1.8 \mu \mathrm{M}$ $\left.\mathrm{TPP}^{+}-\mathrm{Cl}\right)$ and the mitochondrial matrix with a $\mathrm{TPP}^{+}$-sensitive electrode (Kamo et al., 1979; Brustovetsky and Dubinsky, 2000). A decrease of external $\mathrm{TPP}^{+}$concentration corresponds to mitochondrial polarization, whereas an increase of $\mathrm{TPP}^{+}$in the medium corresponds to depolarization. Mitochondrial swelling was measured as a change of light scattering with a photodiode light detector in combination with laser light $(670 \mathrm{~nm})$ delivered through a light guide (Brustovetsky et al., 2002). Quantitative comparisons of the rate of swelling were made between the light scattering slopes during the first minute after $\mathrm{Ca}^{2+}$ addition. Mitochondrial $\mathrm{Ca}^{2+}$ uptake was monitored with a $\mathrm{Ca}^{2+}$-selective electrode as described previously (Brustovetsky and Dubinsky, 2000). Oxygen consumption was monitored in a closed chamber under identical conditions with a Clark-type electrode (Brustovetsky and Dubinsky, 2000). Unless indicated otherwise, antagonists were added to the test media before mitochondrial addition. All data traces shown are representative of at least three replicates.

ATP and ADP content. ADP and ATP [adenine nucleotides (AdNs)] were determined using a luciferin/luciferase ATP detection kit (Sigma, St. Louis, MO) and a Monolight 3010 luminometer (PharMingen, San Diego, CA). AdNs were measured immediately after isolation of mitochondria either in mitochondrial suspensions stored on ice or in mitochondrial suspensions incubated in incubation medium with respiratory substrates at $37^{\circ} \mathrm{C}$ with or without $\mathrm{Ca}^{2+}$. In all cases ATP was measured in $2 \%$ perchloric acid extracts neutralized by $\mathrm{KOH}$ following the kit manufacturer's suggestions. ADP was converted to ATP using pyruvate kinase (Kimmich et al., 1975).

Immunoblotting. Cortical and striatal tissue homogenates were prepared as in the first step of the mitochondrial isolation in proteasecontaining solutions for loading onto $12 \%$ Bis-Tris MOPS gels (Novex Electrophoresis, Invitrogen). Three micrograms of denatured protein suspended in loading buffer were applied per lane. Proteins were transferred to nitrocellulose membrane in NuPage transfer buffer, and antibodies (Chemicon, Temecula, CA) to neuronal nuclear protein (NeuN; 1:500) and glial fibrillary acidic protein (GFAP; 1:75,000) were applied for $1 \mathrm{hr}$. The secondary antibody was HRP-conjugated mouse anti-goat IgG. Identified proteins were visualized using enhanced Supersignal chemiluminescence (Pierce, Rockford, IL). Blots were then stripped in $1 \mathrm{~N} \mathrm{HCl}$ for $1 \mathrm{hr}$ and reprobed with antibodies to actin (1:75,000). Densitometry was performed using the Bio-Rad Molecular Analyst Software.

Reactive oxygen species production. Production of reactive oxygen species (ROS) by brain mitochondria was monitored using the Amplex Red assay for $\mathrm{H}_{2} \mathrm{O}_{2}$ (Molecular Probes, Eugene, OR) (Votyakova and Reynolds, 2001) and $2^{\prime} 7^{\prime}$-dichlorofluorescin diacetate $\left(\mathrm{H}_{2}\right.$-DCFDA) as a membrane-permeable probe for $\mathrm{H}_{2} \mathrm{O}_{2}$, nitric oxide, and other ROS (Molecular Probes) (LeBel et al., 1992; Maciel et al., 2001). $\mathrm{H}_{2}$-DCFDA was dissolved in methanol at $2 \mathrm{~mm}$ and kept under nitrogen until use. Stock solutions were made on a daily basis. Mitochondria (50 $\mu$ g protein) were incubated in a standard incubation medium supplemented either with 2 $\mu \mathrm{M}$ Amplex Red and $1 \mathrm{U} / \mathrm{ml}$ horseradish peroxidase or with $2 \mu \mathrm{M} \mathrm{H}_{2}-$ DCFDA in a $400 \mu \mathrm{l}$ cuvette at $37^{\circ} \mathrm{C}$ with continuous stirring. To load mitochondria with $\mathrm{H}_{2}$-DCFDA, $100 \mu$ l of mitochondrial suspension (2.5 mg protein/ml) was incubated with $20 \mu \mathrm{M} \mathrm{H}_{2}$-DCFDA at $22^{\circ} \mathrm{C}$ for $30 \mathrm{~min}$ followed by centrifugation at $15,800 \times g$ for 5 min (Maciel et al., 2001). The supernatant was aspirated and the pellet was resuspended in the same volume of the fresh mitochondrial storage buffer. Fluorescence of oxidized Amplex Red or $\mathrm{H}_{2}$-DCFDA was measured in a Perkin-Elmer LS 55 spectrofluorimeter using excitation/emission wavelengths 550/590 $\mathrm{nm}$ and $490 / 526 \mathrm{~nm}$, respectively. Because $\mathrm{H}_{2}$-DCFDA is $\mathrm{pH}$ sensitive and fluorescence is quenched under acidic conditions, mitochondrial $\mathrm{pH}$ changes were followed in parallel experiments by measuring the fluorescence of $1 \mu \mathrm{M}$ 2',7'-bis-(2-carboxyethyl)-5-(and-6)-carboxyfluorescein (BCECF) (excitation/emission wavelengths 588/535 nm).

Mitochondrial cyclophilin D. Mitochondrial cyclophilin D (CyP-D) contents were determined immunologically. Mitochondria purified from striatal and cortical tissue were denatured in SDS-PAGE sample loading buffer and loaded at concentrations of $10 \mu \mathrm{g}$ protein per lane. After electrophoresis, proteins were blotted onto nitrocellulose in $\mathrm{pH} 9.0$ buffer. CyP-D was detected with a polyclonal antibody raised against the peptide CSDGGARGANSSSQNP, which corresponds to residues $1-16$ of rat $\mathrm{CyP}-\mathrm{D}$ after cleavage of the mitochondrial targeting sequence. Peroxidase-conjugated, goat anti-rabbit IgG (Bio-Rad) was used as a secondary antibody, and bands were developed with the enhanced chemiluminescence reagent from Amersham Biosciences. As a marker, we used CyP-D excised from recombinant glutathione $S$-transferase CyP-D fusion protein (Crompton et al., 1998) with thrombin and purified by cation exchange FPLC (Andreeva et al., 1995). Blots were then stripped in $1 \mathrm{~N} \mathrm{HCl}$ for $1 \mathrm{hr}$ and reprobed with antibodies to voltagedependent anion channel (VDAC) (1:60,000) (Chemicon). Visualization of VDAC was identical to that for NeuN and GFAP.

Statistics. All summary data represent mean \pm SEM of three to nine experimental replicates. Dose-response data were fitted with sigmoid curves (Graphpad Prism), and the $\log \mathrm{ED}_{50}$ values were compared using weighted, paired $t$ tests by statistical consultants. Other data were compared using one-way ANOVAs followed by Bonferroni's multiple comparison test.

\section{Results}

Mitochondria were isolated from striatum and cortex and incubated in $125 \mathrm{~mm} \mathrm{KCl}$ medium to approximate cytosolic conditions. $\mathrm{TPP}^{+}$accumulation, indicative of $\Delta \psi$, was similar in both types of mitochondria. $\mathrm{Ca}^{2+}$ addition typically produces a transient depolarization because of its electrophoretic entry and subsequent compensation by respiratory fluxes, followed by a steady-state depolarization indicative of the extent of mPT opening (Brustovetsky and Dubinsky, 2000). Surprisingly, striatal mitochondria were more sensitive than cortical mitochondria to $\mathrm{Ca}^{2+}$, consistently depolarizing and swelling at lower $\left[\mathrm{Ca}^{2+}\right]$ (Fig. 1): $0.3 \mu \mathrm{mol} \mathrm{Ca}{ }^{2+} / \mathrm{mg}$ protein caused rapid swelling of striatal mitochondria followed by shrinkage caused by volume compensation by an unknown mechanism. This was accompanied by a complete sustained depolarization. Cortical mitochon- 

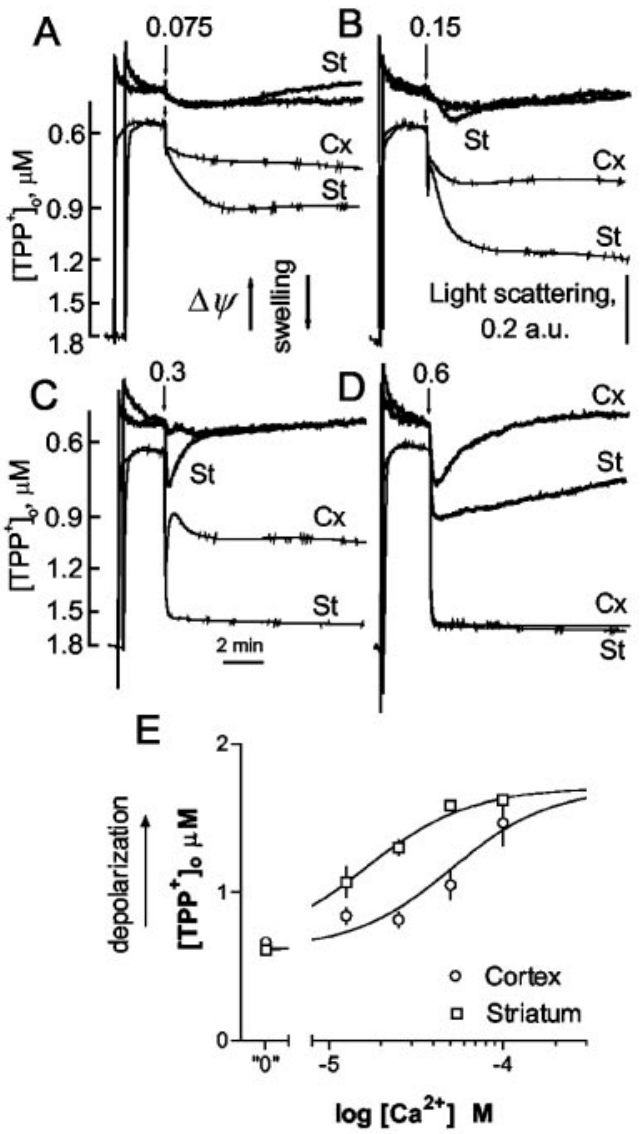

Figure 1. Calcium sensitivity of striatal $(\mathrm{St})$ and cortical $(\mathrm{C} \mathrm{X})$ mitochondria in $\mathrm{KCl}$-based medium. $A-D$, Mitochondrial TPP ${ }^{+}$accumulation $(\Delta \psi$, thin lines) and light scattering (swelling, thick lines) were monitored in response to the indicated $\mathrm{Ca}^{2+}$ pulses presented in micromoles of $\mathrm{Ca}^{2+}$ per milligram of mitochondrial protein $(A-D) . E$, External TPP ${ }^{+}$concentrations $\left(\left[\mathrm{TPP}^{+}\right]_{0}\right) 5$ min after $\mathrm{Ca}^{2+}$ addition as a function of added $\mathrm{Ca}^{2+}$. In all figures, numbers and arrows indicate $\mathrm{Ca}^{2+}$ addition in micromoles per milligram of protein. Curves shown are drawn through the averaged data points. Statistical comparisons were made between curves fitted to the data of each individual day.

dria responded to the same $\mathrm{Ca}^{2+}$ pulse by partial depolarization without swelling: $0.6 \mu \mathrm{mol} \mathrm{Ca}{ }^{2+} / \mathrm{mg}$ protein resulted in a complete sustained depolarization of cortical mitochondria paralleled by transient swelling. In these conditions the compensatory shrinkage was slowed considerably in striatal mitochondria. Depolarization in striatal mitochondria occurred at statistically significant lower concentrations than in cortical mitochondria (Fig. $1 E)\left(\operatorname{logED}{ }_{50}\right.$ for striatal mitochondria $-4.75 \pm 0.11$ vs $-4.07 \pm$ 0.15 for cortical mitochondria; $n=4 ; p<0.01$ ). The increased sensitivity of striatal mitochondria to $\mathrm{Ca}^{2+}$-induced depolarization and swelling was also observed when mitochondria were incubated in $75 \mathrm{~mm} \mathrm{KCl}$ medium or energized by pyruvate plus malate (data not shown).

To test whether the observed difference between striatal and cortical mitochondria was dependent on the KCl-based medium, mannitol-sucrose-based medium (MS) was used. As in $\mathrm{KCl}$, in MS, the initial $\mathrm{TPP}^{+}$accumulation was equal in both types of mitochondria, indicating similar energization. However, TPP ${ }^{+}$ accumulation was greater in $\mathrm{MS}$ than in $\mathrm{KCl}$, indicating a more polarized $\Delta \psi$. The lower $\Delta \psi$ in $\mathrm{KCl}$ might be consequent to $\mathrm{K}^{+}$ cycling or other processes (Garlid and Paucek, 2001). In MS, 0.3 $\mu \mathrm{mol} \mathrm{Ca}^{2+} / \mathrm{mg}$ protein produced a transient depolarization without large amplitude swelling in both striatal and cortical mi-

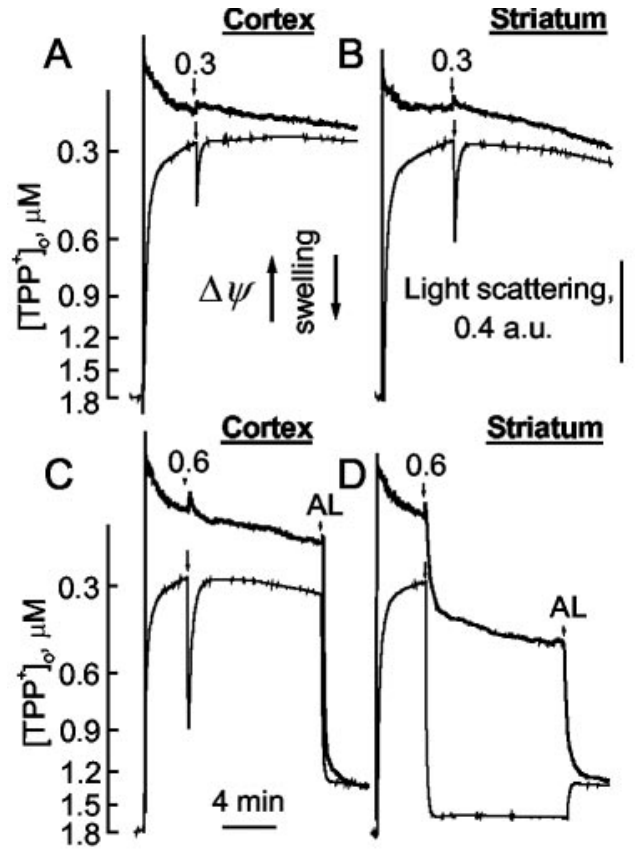

Figure 2. Calcium sensitivity of striatal and cortical mitochondria in mannitol-sucrose medium. Measurements and symbols are as in Figure 1. Alamethicin (AL) (30 $\mu \mathrm{g} / \mathrm{ml})$ produced maximal swelling.

tochondria (Fig. 2). Larger $\mathrm{Ca}^{2+}$ pulses $\left(0.6 \mu \mathrm{mol} \mathrm{Ca}{ }^{2+} / \mathrm{mg}\right.$ protein) caused a complete sustained depolarization of striatal, but not cortical, mitochondria accompanied by large-amplitude swelling reaching $\sim 50 \%$ of maximal, alamethicin-induced amount. Both the $\mathrm{Ca}^{2+}$-induced sustained depolarization and large-amplitude swelling are typical manifestations of the classical mPT (Zoratti and Szabo, 1995). Thus, $\mathrm{Ca}^{2+}$ depolarized and induced large-amplitude swelling more readily in striatal than cortical mitochondria.

Mitochondrial depolarization could be caused by increased permeability of the inner mitochondrial membrane, inhibition of respiration, or both. Respiratory measurements were obtained to distinguish between these possibilities. Oxygen consumption (Fig. 3) was comparable for both types of mitochondria, whether with ADP (state 3) or after ADP depletion (state 4). These measurements were similar between the two tissue types whether the mitochondria were respiring on the complex I substrates, pyruvate plus malate, or the complex II substrate, succinate (plus glutamate to remove oxaloacetate, an inhibitor of succinate dehydrogenase, by transamination) (Lehninger et al., 1993). However, when energized with pyruvate plus malate, $\mathrm{Ca}^{2+}$ decreased oxygen consumption equally in the two types of mitochondria. The $\mathrm{Ca}^{2+}$-induced respiratory inhibition could be caused by inhibition of complex I or loss of endogenous $\mathrm{NAD}(\mathrm{P}) \mathrm{H}$ as a result of the mPT. Thus, inhibition of respiration by $\mathrm{Ca}^{2+}$ may have contributed to depolarization of both types of mitochondria oxidizing pyruvate plus malate. The uncoupler, 2,4-dinitrophenol, equally activated respiration of both types of mitochondria incubated with either pyruvate plus malate or succinate plus glutamate. When energized with succinate plus glutamate, $\mathrm{Ca}^{2+}$ produced a greater increase in respiration in striatal mitochondria than in cortical mitochondria, indicating uncoupling of striatal mitochondria consistent with stronger depolarization. Thus, the $\mathrm{Ca}^{2+}$-induced depolarization with succinate plus glutamate was caused by increased permeability of the inner mitochondrial 


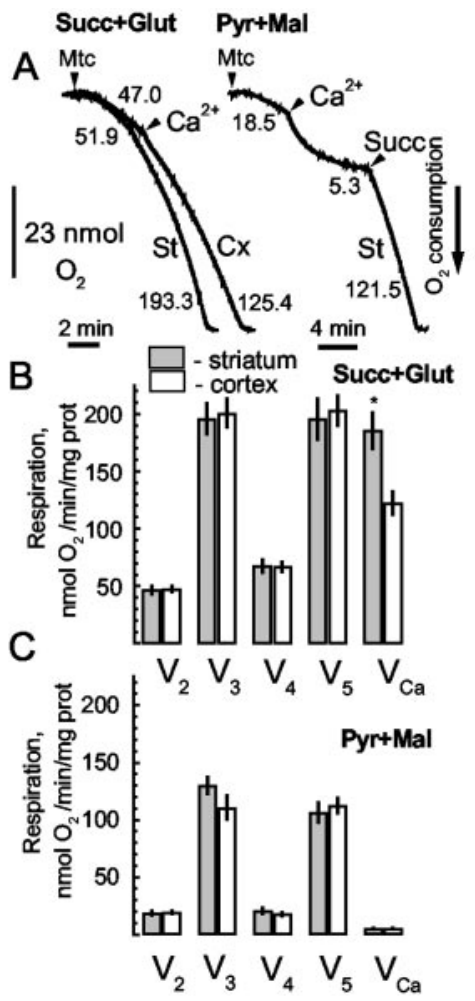

Figure 3. Oxygen consumption of cortical and striatal mitochondria respiring on $3 \mathrm{~mm}$ succinate and $3 \mathrm{~mm}$ glutamate $(A, B)$ or $3 \mathrm{~mm}$ pyruvate and $1 \mathrm{~mm}$ malate $(A, C)$ in respiratory states 2 ( $V_{2}$, before ADP addition), $3\left(V_{3}\right.$, after ADP addition), $4\left(V_{4}\right.$, after ADP depletion), and $5\left(V_{5}\right.$ after addition of $40 \mu \mathrm{m}$ 2,4-dinitrophenol) and in response to $0.3 \mu \mathrm{mol} \mathrm{Ca}{ }^{2+} / \mathrm{mg}$ protein $\left(V_{\mathrm{Ca}^{2+}}{ }^{2+}\right.$. Respiratory rates from three to six experiments $(A)$ were averaged and compared in $B$ and $C .{ }^{*} p<0.01$ comparing striatal with cortical mitochondria.

membrane rather than inhibition of respiration. Under such conditions striatal mitochondria would both produce less ATP and more actively hydrolyze existing ATP attributable to reversal of ATP synthase.

Cyclosporin A (CsA) $(1 \mu \mathrm{M})$, an antagonist of the $\mathrm{mPT}$ and ligand for CyP-D (Crompton et al., 1988; Broekemeier et al., 1989; Halestrap and Davidson, 1990; McGuinness et al., 1990), essentially prevented the mitochondrial depolarization and transient swelling in response to $0.3 \mu \mathrm{mol} \mathrm{Ca}{ }^{2+} / \mathrm{mg}$ protein in both types of mitochondria (Fig. 4); however, in striatal mitochondria, but not cortical mitochondria, $0.6 \mu \mathrm{mol} \mathrm{Ca}^{2+} / \mathrm{mg}$ protein overcame the CsA inhibition.

ADP is another potent blocker of the MPT (Hunter and Haworth, 1979; LeQuoc and LeQuoc, 1988; Halestrap and Davidson, 1990; Brustovetsky and Dubinsky, 2000). When $100 \mu \mathrm{M}$ ADP was added before the $\mathrm{Ca}^{2+}$ challenge, a transient depolarization occurred because of activation of oxidative phosphorylation (Fig. 5A-D). In these conditions the $\mathrm{Ca}^{2+}$-induced depolarizations and swelling were essentially prevented in both types of mitochondria (Fig. $5 C, D$ ), even after challenges by $0.6 \mu \mathrm{mol}$ $\mathrm{Ca}^{2+} / \mathrm{mg}$ protein (data not shown). Thus the AdNs were stronger antagonists than CsA, equalizing the responses of cortical and striatal mitochondria to $\mathrm{Ca}^{2+}$.

Mitochondrial $\mathrm{Ca}^{2+}$ uptake consistently reflected mitochondrial depolarization in response to added $\mathrm{Ca}^{2+}$. Striatal mitochondria sequestered less $\mathrm{Ca}^{2+}$ than cortical mitochondria in response to increasing concentrations of $\mathrm{Ca}^{2+}$ (Fig. 6A,C). CsA or ADP improved $\mathrm{Ca}^{2+}$ uptake to comparable levels in both types
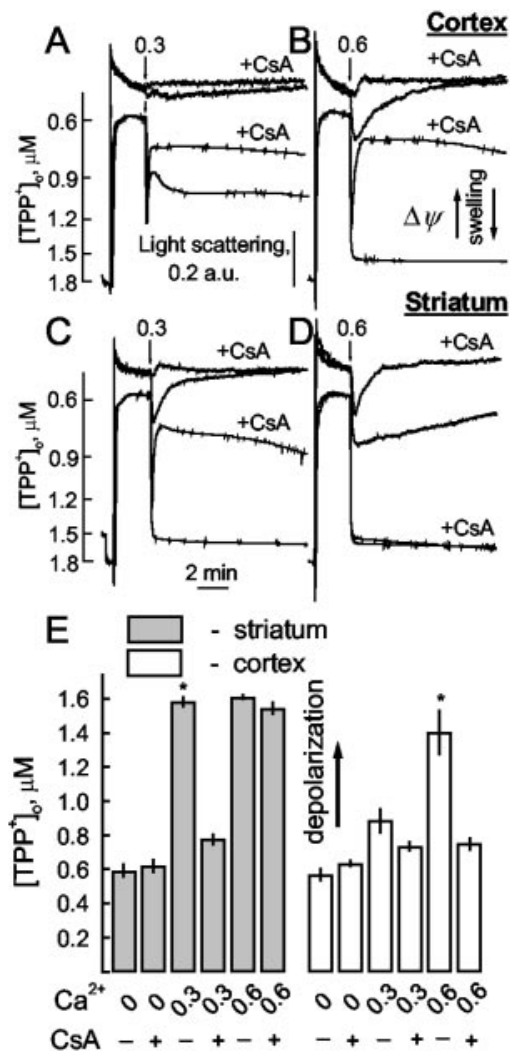

Figure 4. $\quad \mathrm{CA}(1 \mu \mathrm{M})$ prevented $\mathrm{Ca}^{2+}$-induced depolarization and swelling in both cortical $(A, B)$ and striatal $(C, D)$ mitochondria, but this inhibition was overcome by lower $\left[\mathrm{Ca}^{2+}\right]$ in striatal mitochondria $(B, D)$. Traces are the same as in Figure 1.E, Summary of averaged $\left[\operatorname{TPP}^{+}\right]_{0}$ measurements before or 5 min after $\mathrm{Ca}^{2+}$ addition from three to eight experiments applying 1 $\mu \mathrm{M} C \mathrm{SA}$ as antagonist. ${ }^{*} p<0.001$ versus measurements with the same $\mathrm{Ca}^{2+}$ in the presence of CSA.

of mitochondria, paralleling their restoration of the $\Delta \psi$ response to $\mathrm{Ca}^{2+}$ (Fig. 6B).

Thus, striatal mitochondria were more sensitive to $\mathrm{Ca}^{2+}$ than cortical mitochondria. This could contribute to the greater vulnerability of striatal cells to the stresses of HD. To understand the causes of the supersensitivity of striatal mitochondria to $\mathrm{Ca}^{2+}$, we tested several hypotheses.

\section{AdN hypothesis}

Because exogenous ADP eliminated the difference between striatal and cortical mitochondria, the higher sensitivity of striatal mitochondria to $\mathrm{Ca}^{2+}$ could be caused by lower endogenous $\mathrm{ADP}$ and/or ATP, as has been shown previously for MPT induction in cortex, hippocampus, and cerebellum (Friberg et al., 1999). However, ADP and ATP content were identical in striatal and cortical mitochondria, either stored on ice or energized with succinate plus glutamate at $37^{\circ} \mathrm{C}$ (Fig. $7 \mathrm{~A}, \mathrm{~B}$ ). AMP does not antagonize the mPT (Halestrap et al., 1997) and therefore was not measured. In energized mitochondria, the high ATP/ADP ratio corresponded to the high $\Delta \psi$. Differences in ATP and ADP content between striatal and cortical mitochondria were observed after $\mathrm{Ca}^{2+}$ challenges (Fig. $7 B$ ). Under these conditions, striatal mitochondria had lower ATP content and higher ADP levels than cortical mitochondria, consistent with stronger depolarization (Fig. $7 B$ ). This response could be caused by a decreased amount of ATP production by the $\mathrm{Ca}^{2+}$-depolarized mitochondria or an increased hydrolysis of existing endogenous ATP, or both. Thus, 

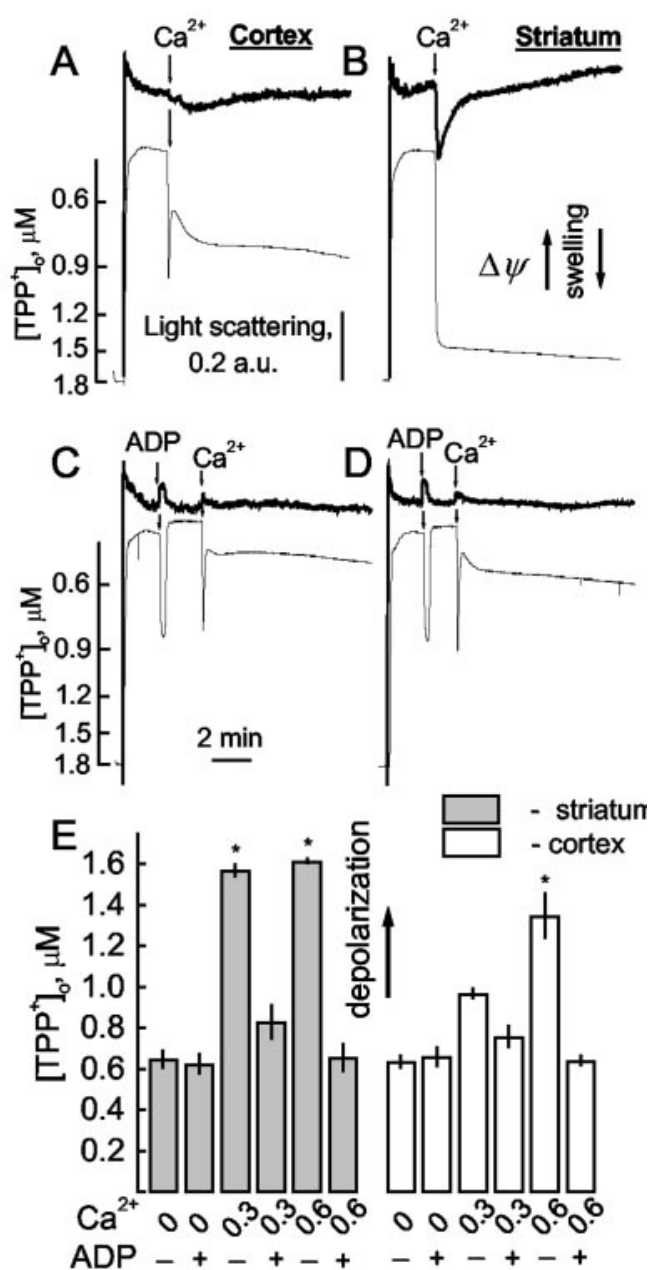

Figure 5. ADP antagonized $\mathrm{Ca}^{2+}$-induced depolarization and swelling. Depolarizations and swelling in cortical $(A, C)$ and striatal mitochondria $(B, D)$ were prevented by $\operatorname{ADP}(C, D)$. E, Summary of TPP ${ }^{+}$measurements from three to eight experiments applying ADP as antagonist. Averaged $\left[\mathrm{TPP}^{+}\right]_{0}$ before or $5 \mathrm{~min}$ after $\mathrm{Ca}^{2+}$ addition with or without $100 \mu \mathrm{M} \mathrm{ADP.}{ }^{*} p<$ 0.001 versus measurements with the same $\mathrm{Ca}^{2+}$ in the presence of ADP.

tissue-specific differences in ADP or ATP content before a $\mathrm{Ca}^{2+}$ challenge could not explain the striatal supersensitivity.

\section{ROS hypothesis}

An increased production of ROS in striatal mitochondria could mediate the observed differences. To test this, an Amplex Red assay and membrane-permeable ROS-sensitive fluorescent dye $\mathrm{H}_{2}$-DCFDA were used to measure $\mathrm{H}_{2} \mathrm{O}_{2}$ release in the medium or ROS production in mitochondria, respectively (Maciel et al., 2001; Votyakova and Reynolds, 2001). Initial rates of increase of Amplex Red and $\mathrm{H}_{2}$-DCFDA fluorescence were equal in both types of mitochondria (Figs. 8, 9). With Amplex Red, $\mathrm{Ca}^{2+}$ produced a dose-dependent decrease in the rate of ROS production, as expected for the accompanying depolarization (Korshunov et al., 1997; Votyakova and Reynolds, 2001). For a given $\mathrm{Ca}^{2+}$ pulse, the rate of ROS production was less for striatal mitochondria compared with cortical mitochondria, consistent with the greater depolarization.

In contrast to the Amplex Red measurements, the $\mathrm{H}_{2}$-DCFDA assay reported $\mathrm{Ca}^{2+}$-induced activation of ROS production (Fig. 9 ). Increases in the $\mathrm{H}_{2}$-DCFDA signal were observed when the $\mathrm{H}_{2}$-DCFDA was present in both the medium and mitochondria and in only the mitochondria (data not shown). No differences
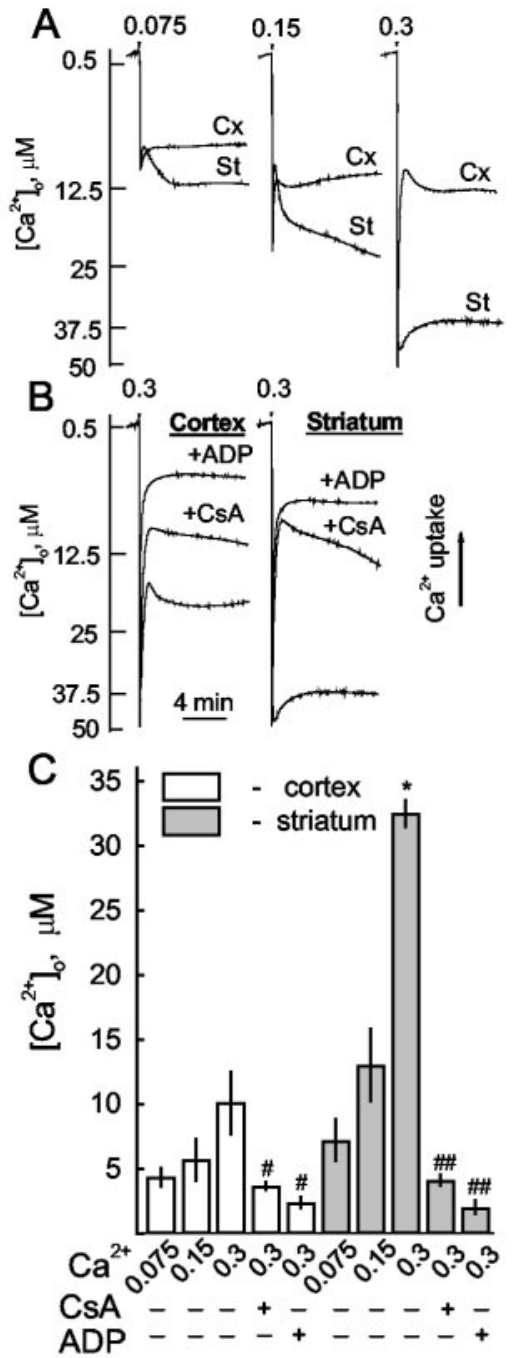

Figure 6. Calcium uptake was depressed in striatal (St) compared with cortical (CX) mitochondria for similar $\mathrm{Ca}^{2+}$ additions $(A)$. CSA $(1 \mu \mathrm{M})$ or ADP $(100 \mu \mathrm{M})$ increased $\mathrm{Ca}^{2+}$ uptake to comparable levels in both tissues $(B) . C$, External $\left[\mathrm{Ca}^{2+}\right] 5 \mathrm{~min}$ after indicated $\mathrm{Ca}^{2+}$ additions reflects differences in mitochondrial type and the presence of CSA or ADP. ${ }^{*} p<0.001$ striatal mitochondria compared with cortical mitochondria. ${ }^{\#} p<0.01,{ }^{\# \#} p<$ 0.001 compared with $\mathrm{Ca}^{2+}$ addition in the same type of mitochondria in the absence of antagonist.

were observed between $\mathrm{Ca}^{2+}$ responses in striatal and cortical mitochondria. As a control, pH changes in the incubation medium that could affect the $\mathrm{H}_{2}$-DCFDA signal were monitored with BCECF. $\mathrm{Ca}^{2+}$ produced a similar acidification in both types of mitochondria that could not explain the increased $\mathrm{H}_{2}$-DCFCA fluorescence (data not shown). The difference between the two assays could be caused by interaction of the dyes with different ROS species. With succinate, Amplex Red could report reversed electron transport-driven ROS production in complex I, which is very sensitive to depolarization (Korshunov e al., 1997; Votyakova and Reynolds, 2001). $\mathrm{H}_{2}$-DCFDA probably reported ROS derived from the ubiquinone cycle, which appears to be insensitive to changes of $\Delta \psi$ (Boveris et al., 1976; Turrens et al., 1985; Votyakova and Reynolds, 2001). Besides, Amplex Red may report ROS outside the mitochondria, whereas $\mathrm{H}_{2}$-DCFDA could be reacting mainly with ROS inside the mitochondria. The apparently controversial results obtained with both assays are consistent with existing data obtained in the other laboratories using 


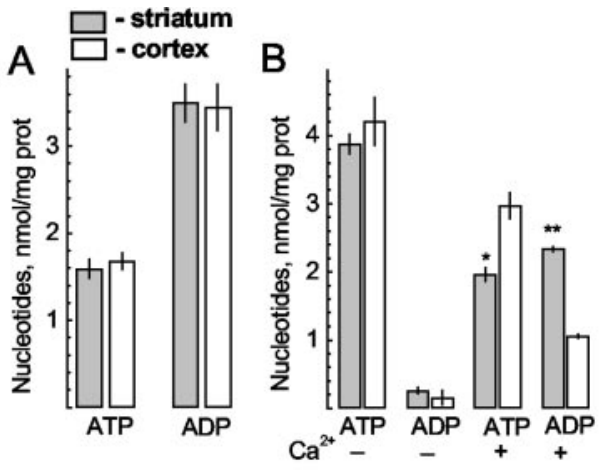

Figure 7. Adenine nucleotide content was comparable between striatal and cortical mitochondria under all conditions except after addition of $0.3 \mu \mathrm{mol} \mathrm{Ca}^{2+} / \mathrm{mg}$ protein. AdNs were assayed in mitochondrial suspension (100 $\mu \mathrm{l}, 20 \mu \mathrm{g}$ protein) taken after either storage on ice $(A)$ or incubation in the incubation medium at $37^{\circ} \mathrm{C}(B)$, before or $5 \mathrm{~min}$ after addition of 0.3 $\mu \mathrm{mol} \mathrm{Ca}{ }^{2+} / \mathrm{mg}$ protein at $37^{\circ} \mathrm{C}{ }^{*} p<0.01,{ }^{* *} p<0.001$ comparing striatum with cortex.
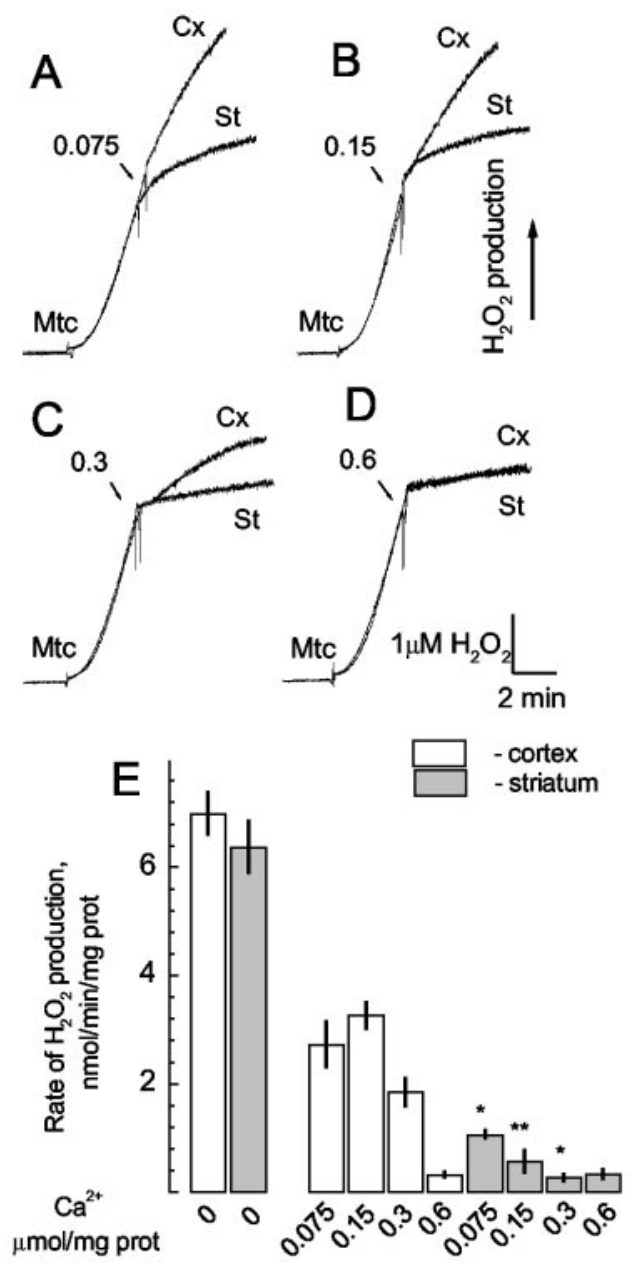

Figure 8. $\mathrm{H}_{2} \mathrm{O}_{2}$ production monitored by Amplex Red fluorescence decreased in striatal (St) mitochondria more than in cortical $(\mathrm{CX})$ mitochondria in response to the indicated doses of $\mathrm{Ca}^{2+}(A-D)$. E, Averaged initial slopes of the Amplex Red traces indicate differing rates of $\mathrm{H}_{2} \mathrm{O}_{2}$ production. ${ }^{*} p<0.01,{ }^{* *} p<0.001$ striatum compared with cortex.

these dyes (Korshunov et al., 1997; Maciel et al., 2001; Votyakova and Reynolds, 2001). In addition to reporting an increase in ROS in response to $\mathrm{Ca}^{2+}$, the $\mathrm{H}_{2}$-DCFDA experiments failed to distinguish between striatal and cortical mitochondria. Neither measurement, however, indicated a differential in-

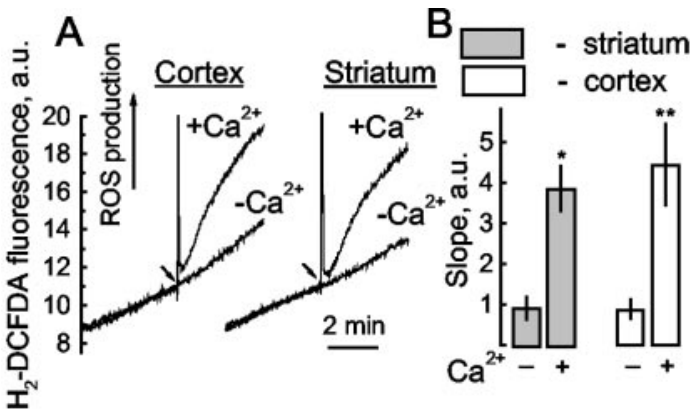

Figure 9. ROS generation monitored with $\mathrm{H}_{2}-\mathrm{DCFDA}$ before and after addition of $0.3 \mu \mathrm{mol}$ $\mathrm{Ca}^{2+} / \mathrm{mg}$ protein in cortical and striatal mitochondria $(A) . B$, Comparisons of initial rates of $\mathrm{H}_{2}$-DCFDA fluorescence increase (mean \pm SEM) in both types of mitochondria. ${ }^{*} p<0.05$, ${ }^{* *} p<0.01$ after $\mathrm{Ca}^{2+}$ compared with control for the same type of mitochondria.

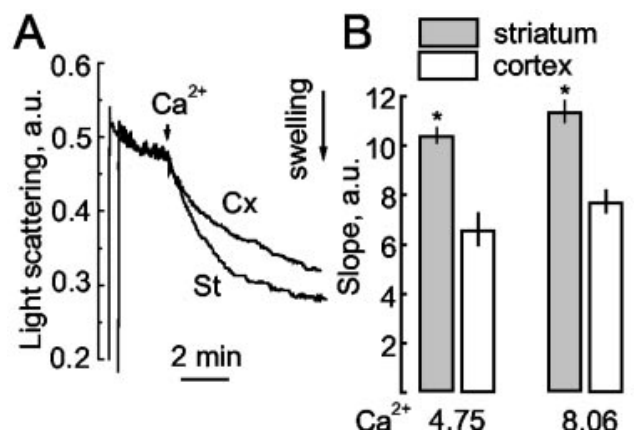

Figure 10. Mitochondrial swelling under de-energized conditions. $A$, Light scattering traces in response to $8.06 \mu \mathrm{mol} \mathrm{Ca}^{2+} / \mathrm{mg}$ protein from one of three such experiments. $B$, Initial slopes of the light scattering traces in response to two different $\left[\mathrm{Ca}^{2+}\right]$. Free $\left[\mathrm{Ca}^{2+}\right]$ was calculated using MaxChelator v. 2.10 (www.stanford.edu/ cpatton/downloads.htm). ${ }^{*} p<0.01$ comparing striatum versus cortex.

crease in ROS production that could explain the striatal supersensitivity to $\mathrm{Ca}^{2+}$.

$\mathrm{Ca}^{2+}$ uptake or release hypothesis

Differences in the initial $\mathrm{Ca}^{2+}$ content or $\mathrm{Ca}^{2+}$ influx or efflux rates between striatal and cortical mitochondria might account for the observed differences. To test these, $\mathrm{Ca}^{2+}$-induced swelling was monitored in de-energized mitochondria in the presence of the $\mathrm{Ca}^{2+}$ ionophore, A23187 (Fig. 10). Any initial inequities in mitochondrial $\left[\mathrm{Ca}^{2+}\right]$ would be removed in the presence of ionophore. Although higher $\left[\mathrm{Ca}^{2+}\right]$ was necessary to produce swelling in these nonfunctional conditions, striatal mitochondria continued to be more sensitive. Thus, differences in $\mathrm{Ca}^{2+}$ uptake via the uniporter or $\mathrm{Ca}^{2+}$ release via the $\mathrm{Na}^{+} / \mathrm{Ca}^{2+}$ exchanger could not account for the striatal supersensitivity.

\section{Different mitochondrial populations hypothesis}

One possible explanation for the differential response of striatal compared with cortical mitochondria could be different populations of mitochondria within the two tissues. Large differences in the relative numbers of neurons and glia could result in differing proportions of neuronal and glial mitochondria between the two tissues. Differences in the contribution of mitochondria from oligodendrocytes were considered to be minimal because oligodendrocyte somas are smaller than neuronal or astrocyte somas, and the compacted myelin of oligodendrocyte processes contains no cytoplasm. Cortical tissue used for mitochondrial preparation contained white matter just as striatal tissue contained myelin- 


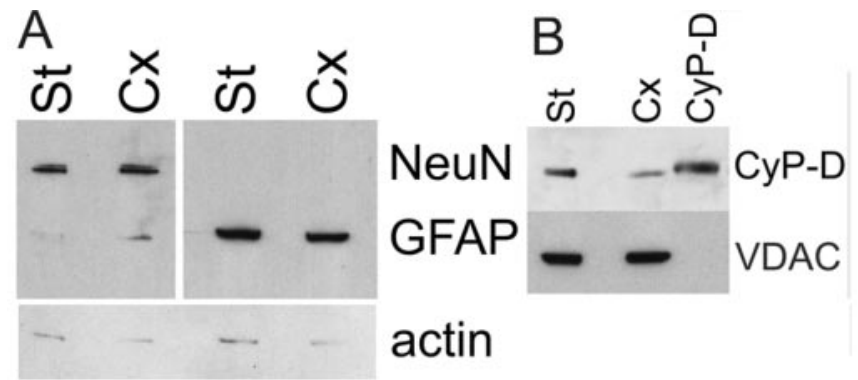

Figure 11. Immunoblots of marker proteins in striatal and cortical brain tissue $(A)$ and isolated mitochondria ( $B)$. A, Immunodetection of NeuN (66 kDa), GFAP (51 kDa), and actin (42 $\mathrm{kDa}$ ) from different regions of the same rat brain. The monoclonal NeuN antibody also detects a faint band at $50 \mathrm{kDa}$. B, Immunodetection of CyP-D (16.5 kDa) and VDAC (30 kDa) from mitochondria prepared from cortex and striatum of the same animal. The lane marked CyP-D represents $7 \mu \mathrm{g}$ of purified CyP-D standard. Immuoblots shown are representative of replicates from three to six different animals.

ated fibers of the internal capsule. To determine the relative proportions of astrocytes and neurons in the starting material, immunoblots of cortical and striatal tissue were probed for the astroglial marker protein GFAP, the neuronal nuclear marker protein NeuN, and actin (Fig. 11A). No differences were observed in the relative intensities of the immunoblots. mRNA levels for GFAP have been reported to be equal for striatum and cortex (Bendotti et al., 1994). Thus the proportion of astrocytes to neurons in each tissue type appeared to be comparable, and differences in the proportion of neuronal and glial mitochondria could not account for the increased susceptibility of striatal mitochondria to a $\mathrm{Ca}^{2+}$-activated $\mathrm{mPT}$.

\section{CyP-D hypothesis}

CyP-D is an important component of the mPT pore complex responsible for CsA sensitivity (Halestrap and Davidson, 1990; McGuinness et al., 1990). CyP-D binds directly to the adenine nucleotide translocase (ANT), a putative translocating pathway of the mPT pore complex (Crompton et al., 1998), and increases the probability of $\mathrm{Ca}^{2+}$-induced conversion of the ANT into a large channel (Woodfield et al., 1998). The increased susceptibility of striatal mitochondria to the $\mathrm{Ca}^{2+}$-induced $\mathrm{mPT}$ could be caused by a larger amount of CyP-D. To test this hypothesis, the CyP-D content in striatal and cortical mitochondria was evaluated with an antibody to CyP-D by experimenters blinded to the experimental conditions. Striatal mitochondria contained almost twice as much CyP-D as cortical mitochondria (1.8 \pm 0.7 -fold; mean \pm SEM; $n=6$ ) (Fig. $11 B$ ). The larger CyP-D content of striatal mitochondria would facilitate the $\mathrm{mPT}$ and therefore could explain the increased sensitivity of these mitochondria to $\mathrm{Ca}^{2+}$.

\section{Discussion}

These experiments document for the first time that striatal mitochondria may be supersensitive to $\mathrm{Ca}^{2+}$, a property that may contribute to the increased vulnerability of the striatum in HD. $\mathrm{Ca}^{2+}$ triggered larger changes of $\Delta \psi$, calcium uptake, and matrix volume in striatal mitochondria than in cortical mitochondria. In the presence of $\mathrm{Ca}^{2+}$, striatal mitochondria both respired faster and produced less ATP than cortical mitochondria. Thus in striatal mitochondria, more so than cortical mitochondria, $\mathrm{Ca}^{2+}$ appeared to open a large permeability pathway uncoupling oxygen consumption from ATP production. The appearance of mitochondrial swelling at the higher $\mathrm{Ca}^{2+}$ concentrations suggested that this response was attributable to the $\mathrm{mPT}$. At the lower $\mathrm{Ca}^{2+}$ concentrations where swelling was absent or transient, the mitochondrial depolarization could be caused by activating other, lower permeability pathways or fewer permeability transition pores.

The MPT may be a graded or stepwise response associated with variable or increasing levels of permeabilization (Al-Nasser and Crompton, 1986; Broekemeier et al., 1998; Brustovetsky and Dubinsky, 2000). Multiple conductance channels, permeable to $\mathrm{K}^{+}$, have been identified in the inner mitochondrial membrane (Kinnaly et al., 1989; Szabo and Zoratti, 1989, 1991). In brain mitochondria, $\mathrm{Ca}^{2+}$ can activate a low-permeability pathway, permeable to $\mathrm{H}^{+}$and perhaps $\mathrm{K}^{+}$, that produces sustained depolarization without swelling (Brustovetsky and Dubinsky, 2000). In our experiments, replacing $\mathrm{KCl}$ with MS prevented both the transient swelling and sustained depolarization induced by a moderate $\mathrm{Ca}^{2+}$ challenge, suggesting that $\mathrm{K}^{+}$, but not sucrose, could penetrate the $\mathrm{Ca}^{2+}$-activated pathway. Such $\mathrm{K}^{+}$mediated swelling could be compensated by $\mathrm{K}^{+}$extrusion when the $\mathrm{K}^{+} / \mathrm{H}^{+}$exchanger became activated by increased matrix volume producing the observed mitochondrial shrinkage (Halestrap, 1989). In liver mitochondria, $\mathrm{Ca}^{2+}$-induced electrogenic $\mathrm{K}^{+}$uptake and mitochondrial swelling were attributed to pyrophosphate modification of the ANT (Halestrap et al., 1986; Davidson and Halestrap, 1987). $\mathrm{K}^{+}$uptake by liver mitochondria was inhibited by AdNs, suggesting that mitochondria possess $\mathrm{K}_{\mathrm{ATP}}$ channels (Beavis et al., 1993). $\mathrm{K}_{\mathrm{ATP}}$ channels have been isolated from unpurified total brain mitochondria (Bajgar et al., 2001). ADP also inhibits a $\mathrm{Ca}^{2+}$-activated, ANT-linked channel (Brustovetsky and Klingenberg, 1996) as well as mitochondrial swelling and depolarization (Hunter and Haworth, 1979; Halestrap and Davidson, 1990; Novgorodov et al., 1992). In our experiments, ADP as well as CsA completely prevented $\mathrm{Ca}^{2+}$ induced $\mathrm{K}^{+}$-dependent transient swelling of striatal mitochondria, raising the possibility that the $\mathrm{K}^{+}$influx underlying swelling could be mediated by a modified ANT as part of the MPT pore, $\mathrm{K}_{\mathrm{ATP}}$ channels, an as yet unidentified channel, or some combination of pathways. All $\mathrm{Ca}^{2+}$ challenges, however, activating both high and low permeabilities, elicited stronger responses from striatal compared with cortical mitochondria.

Previously, regional differences in $\mathrm{Ca}^{2+}$ sensitivity of mitochondria from hippocampus, cortex, and cerebellum were attributed to differences in the content of endogenous mitochondrial AdNs (Friberg et al., 1999). We did not detect any difference in ADP and ATP content between untreated cortical and striatal mitochondria, consistent with previous measurement in tissue homogenates (Pulsinelli and Duffy, 1983; Nowicki et al., 1988; Yamada et al., 1988; Miyake et al., 1992) (but see Cosi and Marien, 1998). Thus, variations in AdN content cannot explain the striatal supersensitivity. At the same time, excess exogenous ADP effectively protected both striatal and cortical mitochondria. We hypothesize that protection is attributable to the interaction of ADP with a binding site on the ANT or some other $\mathrm{mPT}$-related protein. This binding site might have a lower affinity in striatal mitochondria than in cortical mitochondria. This binding site may correspond to a low-affinity carboxyatractylate (CAT)-insensitive ADP binding site of the ANT described previously (Klingenberg, 1985; Vignais et al., 1989; Halestrap et al., 1997). Indeed, in our experiments CAT failed to abolish ADP protection in both cortical and striatal mitochondria (data not shown). For a given endogenous AdN level, cortical mitochondria appeared to be better protected against $\mathrm{Ca}^{2+}$ than striatal mitochondria. With excess exogenous ADP, the low-affinity 
binding sites became saturated in both types of mitochondria, producing equal protection. In vivo a high proportion of AdNs are complexed with $\mathrm{Mg}^{2+}$ (Davidson and Halestrap, 1987), whereas the ANT binds and transports only free AdNs anions (Duszynski and Wojtczak, 1975; Kramer, 1980). Thus, the low concentrations of endogenous free AdNs may not saturate the low-affinity binding sites of the ANT in striatal mitochondria, predisposing them to $\mathrm{Ca}^{2+}$-induced damage in vivo.

Increased sensitivity of striatal mitochondria to $\mathrm{Ca}^{2+}$ could arise from heterogeneity of regional mitochondria. Heterogeneity among mitochondria from different brain regions has long been recognized as a confounding problem in brain metabolism (Sonnewald et al., 1998). However, the difference in the mitochondrial responses from striatum and cortex do not appear to be attributable to differences in the proportions of neurons or astrocytes in the original tissues. In previous studies measuring metabolic or antioxidant enzyme activities in regional brain mitochondria, variability was consistently high, and striatal and cortical activities were not compared directly, not reported to differ, or changed in opposite directions (Ryder, 1980; Leong et al., 1984; Marzatico et al., 1987; Benzi et al., 1988; Dagani et al., 1988; Curti et al., 1989; Vertechy et al., 1993; Brouillet et al., 1998; Sybirska et al., 2000). Respiratory parameters of isolated mitochondria or whole-brain glucose utilization appear similar in cortex and striatum (Sokoloff et al., 1977; Dagani et al., 1988; Curti et al., 1989) (but see Battino et al., 1991), in agreement with our current data. Striatal medium spiny neurons contain less of the mitochondrially encoded subunit 1 of NADH dehydrogenase (complex I) (ND1) than their neighboring cholinergic and nitric oxide synthase-containing neurons, although the functional consequences of this are unknown (Pettus et al., 2000). These inhibitory neurons may have different energetic needs, using TCA cycle components and recycled glutamate for the synthesis of GABA. GABAergic neurons are more sensitive to 3-nitropropionic acid (3NP) than glutamatergic neurons (Hassel and Sonnewald, 1995), a fact that may explain the Huntington-like symptoms produced by chronic 3NP treatment (Brouillet et al., 1998). Thus although no clear picture emerges of metabolic enzyme differences between these brain regions, perturbation of mitochondrial function consequent to mutant huntingtin production could adversely affect the function of striatal medium spiny neurons before other CNS cells.

Although untreated striatal mitochondria may not differ from cortical ones, when challenged with different stressors, the striatal mitochondria may be more sensitive than cortical mitochondria. Hypoxia produced a decrease in striatal but not cortical succinate dehydrogenase and cytochrome oxidase (Dagani et al., 1984). Cytochrome oxidase and lactate dehydrogenase activity in mitochondria from dorsolateral striatum, but not paramedian cortex, were decreased $24 \mathrm{hr}$ after an ischemic insult (Zaidan and Sims, 1997). Disease states may also stress mitochondrial function. In mitochondria from lymphoblasts of HD patients, the stress of added complex II or IV inhibitors produced much greater depolarization than in controls indicating an increased sensitivity to metabolic inhibition (Sawa et al., 1999). CNS mitochondria from transgenic $\mathrm{HD}$ mice appear more sensitive to $\mathrm{Ca}^{2+}$ induction of the mPT than controls (Panov et al., 2002). Thus enhanced sensitivity to metabolic perturbation of already supersensitive striatal mitochondria could contribute substantially to selective neuronal vulnerability in this region.

Differential expression of various proteins could mediate the observed $\mathrm{Ca}^{2+}$ sensitivity. CyP-D is a peptidylprolyl cis-transisomearse that repairs misfolded proteins. As such, it may act, as do other cyclophilin chaperones, by responding to stress (Andreeva et al., 1999), but its regulation is mostly unstudied. Overexpression of CyP-D protects against oxidant-induced loss of $\Delta \psi$ and delayed cell death after staurosporine exposure in human embryonic kidney and C6 cell lines (Lin and Lechleiter, 2002). CyP-D in conjunction with other chaperones has been proposed as an endogenous regulator of the $\mathrm{mPT}$ in liver (He and Lemasters, 2002), yet apoptotic stimuli have also been observed to decrease CyP-D mRNA in cancer cell lines (Hursting et al., 2002). In brain, the CyP-D content of mitochondria from cortex, hippocampus, and cerebellum did not vary and thus could not explain differences in susceptibility to the $\mathrm{MPT}$ among these brain regions (Friberg et al., 1999). We detected larger amounts of CyP-D in striatal mitochondria than in cortical mitochondria CyP-D sensitizes mitochondria to $\mathrm{Ca}^{2+}$-induced permeabilization of the inner mitochondrial membrane (Halestrap and Davidson, 1990; McGuinness et al., 1990), by interacting directly with the ANT, facilitating the $\mathrm{Ca}^{2+}$-induced conversion of the ANT into a pore (Crompton et al., 1998; Woodfield et al., 1998). CsA inhibits the mPT by binding CyP-D, preventing its interactions with the ANT (Halestrap and Davidson, 1990; McGuinness et al., 1990). Thus, larger amounts of CyP-D in striatal mitochondria may provide more favorable conditions for induction of the $\mathrm{mPT}$ by $\mathrm{Ca}^{2+}$. Larger amounts of CyP-D might result from a higher probability of basal protein misfolding in striatal mitochondria. Because protein misfolding is a known consequence of polyglutamine expansions (Wanker, 2000), this may represent an additional risk factor leading to increased vulnerability of striatal mitochondria and hence striatal neurons in HD.

\section{References}

Al-Nasser I, Crompton M (1986) The reversible $\mathrm{Ca}^{2+}$-induced permeabilization of rat liver mitochondria. Biochem J 239:19-29.

Andreassen OA, Dedeoglu A, Ferrante RJ, Jenkins BG, Ferrante KL, Thomas M, Friedlich A, Browne SE, Schilling G, Borchelt DR, Hersch SM, Ross CA, Beal MF (2001) Creatine increase survival and delays motor symptoms in a transgenic animal model of Huntington's disease. Neurobiol Dis 8:479-491.

Andreeva L, Tanveer A, Crompton M (1995) Evidence for the involvement of a membrane-associated cyclosporin-A-binding protein in the $\mathrm{Ca}\left({ }^{2+}\right)$ activated inner membrane pore of heart mitochondria. Eur J Biochem 230:1125-1132.

Andreeva L, Heads R, Green CJ (1999) Cyclophilins and their possible role in the stress response. Int J Exp Pathol 80:305-315.

Bajgar R, Seetharaman S, Kowaltowski AJ, Garlid KD, Paucek P (2001) Identification and properties of a novel intracellular (mitochondrial) ATPsensitive potassium channel in brain. J Biol Chem 276:33369-33374.

Battino M, Bertoli E, Formiggini G, Sassi S, Gorini A, Villa RF, Lenaz G (1991) Structural and functional aspects of the respiratory chain of synaptic and nonsynaptic mitochondria derived from selected brain regions. J Bioenerg Biomembr 23:345-363.

Beal MF, Brouillet E, Jenkins BG, Ferrante RJ, Kowall NW, Miller JM, Storey E, Srivastava R, Rosen BR, Hyman BT (1993) Neurochemical and histologic characterization of striatal excitotoxic lesions produced by the mitochondrial toxin 3-nitropropionic acid. J Neurosci 13:4181-4192.

Beavis AD, Lu Y, Garlid KD (1993) On the regulation of $\mathrm{K}^{+}$uniport in intact mitochondria by adenine nucleotides and nucleotide analogs. J Biol Chem 268:997-1004

Bendotti C, Baldessari S, Pende M, Tarizzo G, Miari A, Presti ML, Mennini T, Samanin R (1994) Does GFAP mRNA and mitochondrial benzodiazepine receptor binding detect serotonergic neuronal degeneration in rat? Brain Res Bull 34:389-394.

Benzi G, Pastoris O, Villa RF (1988) Changes induced by aging and drug treatment on cerebral enzymatic antioxidant system. Neurochem Res 13:467-478.

Boveris A, Cadenas E, Stoppani AO (1976) Role of ubiquinone in the mitochondrial generation of hydrogen peroxide. Biochem J 156:435-444.

Bradford MM (1976) A rapid and sensitive method for the quantitation of 
microgram quantities of protein utilizing the principle of protein-dye binding. Anal Biochem 72:248-254.

Broekemeier KM, Dempsey ME, Pfeiffer DR (1989) Cyclosporin A is a potent inhibitor of the inner membrane permeability transition in liver mitochondria. J Biol Chem 264:7826-7830.

Broekemeier KM, Klocek CK, Pfeiffer DR (1998) Proton selective substrate of the mitochondrial permeability transition pore-regulation by the redox state of the electron transport chain. Biochemistry 37:13059-13065.

Brouillet E, Guyot MC, Mittoux V, Altairac S, Conde F, Palfi S, Hantraye P (1998) Partial inhibition of brain succinate dehydrogenase by 3-nitropropionic acid is sufficient to initiate striatal degeneration in rat. J Neurochem 70:794-805.

Browne S, Wheeler V, White JK, Fuller SW, MacDonald M, Beal MF (1999) Dose-dependent alterations in local cerebral glucose use associated with the huntingtin mutation in Hdh CAG "knock-in" transgenic mice. Soc Neurosci Abstr 25:543.

Browne SE, Bowling AC, MacGarvey U, Baik MJ, Berger SC, Muqit MM, Bird ED, Beal MF (1997) Oxidative damage and metabolic dysfunction in Huntington's disease: selective vulnerability of the basal ganglia. Ann Neurol 41:646-653.

Brustovetsky N, Dubinsky JM (2000) Dual responses of CNS mitochondria to elevated calcium. J Neurosci 20:103-113.

Brustovetsky N, Klingenberg M (1996) Mitochondrial ADP/ATP carrier can be reversibly converted into a large channel by $\mathrm{Ca}^{2+}$. Biochemistry 35:8483-8488.

Brustovetsky N, Brustovetsky T, Jemmerson R, Dubinsky JM (2002) Calcium-induced cytochrome $c$ release from CNS mitochondria is associated with the permeability transition and rupture of the outer membrane. J Neurochem 80:207-218.

Calabresi P, Centonze D, Pisani A, Bernardi G (1999) Metabotropic glutamate receptors and cell-type-specific vulnerability in the striatum: implication for ischemia and Huntington's disease. Exp Neurol 158:97-108.

Calabresi P, Gubellini P, Picconi B, Centonze D, Pisani A, Bonsi P, Greengard P, Hipskind RA, Borrelli E, Bernardi G (2001) Inhibition of mitochondrial complex II induces a long-term potentiation of NMDA-mediated synaptic excitation in the striatum requiring endogenous dopamine. J Neurosci 21:5110-5120.

Cosi C, Marien M (1998) Decreases in mouse brain $\mathrm{NAD}^{+}$and ATP induced by 1-methyl-4-phenyl-1, 2, 3, 6-tetrahydropyridine (MPTP): prevention by the poly(ADP-ribose) polymerase inhibitor, benzamide. Brain Res 809:58-67.

Crompton M (1999) The mitochondrial permeability transition pore and its role in cell death. Biochem J 341:233-249.

Crompton M, Ellinger H, Costi A (1988) Inhibition by cyclosporin A of a $\mathrm{Ca}^{2+}$-dependent pore in heart mitochondria activated by inorganic phosphate and oxidative stress. Biochem J 255:357-360.

Crompton M, Virji S, Ward JM (1998) Cyclophilin-D binds strongly to complexes of the voltage-dependent anion channel and the adenine nucleotide translocase to form the permeability transition pore. Eur J Biochem 258:729-735.

Curti D, Dagani F, Galmozzi MR, Marzatico F (1989) Effect of aging and acetyl-L-carnitine on energetic and cholinergic metabolism in rat brain regions. Mech Ageing Dev 47:39-45.

Dagani F, Marzatico F, Curti D, Taglietti M, Zanada F, Benzi G (1984) Influence of intermittent hypoxia and pyrimidinic nucleosides on cerebral enzymatic activities related to energy transduction. Neurochem Res 9:1085-1099.

Dagani F, Marzatico F, Curti D (1988) Oxidative metabolism of nonsynaptic mitochondria isolated from rat brain hippocampus: a comparative regional study. J Neurochem 50:1233-1236.

Davidson AM, Halestrap AP (1987) Liver mitochondrial pyrophosphate concentration is increased by $\mathrm{Ca}^{2+}$ and regulates the intramitochondrial volume and adenine nucleotide content. Biochem J 246:715-723.

Dubinsky JM, Levi Y (1998) Calcium-induced activation of the mitochondrial permeability transition in hippocampal neurons. J Neurosci Res 53:728-741.

Duszynski J, Wojtczak L (1975) Effect of metal cations on the inhibition of adenine nucleotide translocation by acyl-CoA. FEBS Lett 50:74-78.

Ferrante RJ, Andreassen OA, Dedeoglu A, Ferrante KL, Jenkins BG, Hersch SM, Beal MF (2002) Therapeutic effects of coenzyme Q10 and remacemide in transgenic mouse models of Huntington's disease. J Neurosci 22:1592-1599.
Friberg H, Connern C, Halestrap AP, Wieloch T (1999) Differences in the activation of the mitochondrial permeability transition among brain regions in the rat correlate with selective vulnerability. J Neurochem 72:2488-2497.

Garlid KD, Paucek P (2001) The mitochondrial potassium cycle. IUBMB Life 52:153-158.

Greene JG, Sheu SS, Gross RA, Greenamyre JT (1998) 3-Nitropropionic acid exacerbates $N$-methyl-D-aspartate toxicity in striatal culture by multiple mechanisms. Neuroscience 84:503-510.

Halestrap AP (1989) The regulation of the matrix volume of mammalian mitochondria in vivo and in vitro and its role in the control of mitochondrial metabolism. Biochim Biophys Acta 973:355-382.

Halestrap AP, Davidson AM (1990) Inhibition of $\mathrm{Ca}^{2+}$-induced largeamplitude swelling of liver and heart mitochondria by cyclosporin is probably caused by the inhibitor binding to mitochondrial-matrix peptidyl-prolyl cis-trans isomerase and preventing it interacting with the adenine nucleotide translocase. Biochem J 268:153-160.

Halestrap AP, Quinlan PT, Whipps DE, Armston AE (1986) Regulation of the mitochondrial matrix volume in vivo and in vitro. The role of calcium. Biochem J 236:779-787.

Halestrap AP, Woodfield KY, Connern CP (1997) Oxidative stress, thiol reagents, and membrane potential modulate the mitochondrial permeability transition by affecting nucleotide binding to the adenine nucleotide translocase. J Biol Chem 272:3346-3354.

Hassel B, Sonnewald U (1995) Selective inhibition of the tricarboxylic acid cycle of GABAergic neurons with 3-nitropropionic acid in vivo. J Neurochem 65:1184-1191.

He L, Lemasters JJ (2002) Regulated and unregulated mitochondrial permeability transition pores: a new paradigm of pore structure and function? FEBS Lett 512:1-7.

Hunter DR, Haworth RA (1979) The $\mathrm{Ca}^{2+}$-induced membrane transition in mitochondria. I. The protective mechanisms. Arch Biochem Biophys 195:453-459.

Hursting SD, Shen JC, Sun XY, Wang TT, Phang JM, Perkins SN (2002) Modulation of cyclophilin gene expression by $N$-4-(hydroxyphenyl)retinamide: association with reactive oxygen species generation and apoptosis. Mol Carcinogen 33:16-24.

Kamo N, Muratsugu M, Hongoh R, Kobatake Y (1979) Membrane potential of mitochondria measured with electrode sensitive to tetraphenyl phosphonium and relationship between proton electrochemical potential and phosphorylation potential in steady state. J Membr Biol 49:105-121.

Kennedy L, Shelbourne PF (2000) Dramatic mutation instability in HD mouse striatum: does polyglutamine load contribute to cell-specific vulnerability in Huntington's disease? Hum Mol Genet 9:2539-2544.

Kimmich GA, Randles J, Brand JS (1975) Assay of picomole amounts of ATP, ADP, and AMP using the luciferase enzyme system. Anal Biochem 69:187-206.

Kinnaly KW, Campo ML, Tedeschi H (1989) Mitochondrial channel activity studied by patch-clamping mitoplasts. J Bioenerg Biomembr 21:497-506.

Klingenberg M (1985) The ADP/ATP carrier in mitochondrial membranes. In: Bioenergetics of electron and proton transport (Martonosi AN, ed), pp 511-551. New York: Plenum.

Korshunov SS, Skulachev VP, Starkov AA (1997) High protonic potential actuates a mechanism of production of reactive oxygen species in mitochondria. FEBS Lett 416:15-18.

Kramer R (1980) Influence of divalent cations on the reconstituted ADP, ATP exchange. Biochim Biophys Acta 592:615-620.

LeBel CP, Ischiropoulos H, Bondy SC (1992) Evaluation of the probe 2', $7^{\prime}$-dichlorofluorescin as an indicator of reactive oxygen species formation and oxidative stress. Chem Res Toxicol 5:227-231.

Lehninger AL, Nelson DL, Cox MM (1993) Principals of biochemistry, Ed 3. New York: Worth Publishers.

Leong SF, Lai JC, Lim L, Clark JB (1984) The activities of some energymetabolising enzymes in nonsynaptic (free) and synaptic mitochondria derived from selected brain regions. J Neurochem 42:1306-1312.

LeQuoc K, LeQuoc D (1988) Involvement of the ADP/ATP carrier in calcium-induced perturbations of the mitochondrial inner membrane permeability: an importance of the orientation of the nucleotide binding site. Arch Biochem Biophys 265:249-257.

Lin DT, Lechleiter JD (2002) Mitochondrial targeted cyclophilin D protects 
cells from cell death by peptidyl prolyl isomerization. J Biol Chem 277:31134-31141.

Maciel EN, Vercesi AE, Castilho RF (2001) Oxidative stress in $\mathrm{Ca}^{2+}$ induced membrane permeability transition in brain mitochondria. J Neurochem 79:1237-1245.

Marzatico F, Dagani F, Curti D, Benzi G (1987) Phenobarbital and 6-aminonicotinamide effect on cerebral enzymatic activities related to energy metabolism in different rat brain areas. Neurochem Res 12:33-39.

McGuinness O, Yafei N, Costi A, Crompton M (1990) The presence of two classes of high-affinity cyclosporin A binding sites in mitochondria. Evidence that the minor component is involved in the opening of an innermembrane $\mathrm{Ca}^{2+}$-dependent pore. Eur J Biochem 194:671-679.

Miyake K, Taguchi T, Tanonaka K, Horiguchi T, Takagi N, Takeo S (1992) Beneficial effects of naftidrofuryl oxalate on brain regional energy metabolism after microsphere-induced cerebral embolism. J Pharmacol Exp Ther 260:1058-1066.

Nicholls DG, Budd SL (1998) Mitochondria and neuronal glutamate excitotoxicity. Biochim Biophys Acta 1366:97-112.

Nicotera P, Ankarcrona M, Bonfoco E, Orrenius S, Lipton SA (1997) Neuronal necrosis and apoptosis: two distinct events induced by exposure to glutamate or oxidative stress. Adv Neurol 72:95-101.

Nicotera P, Leist M, Ferrando-May E (1998) Intracellular ATP, a switch in the decision between apoptosis and necrosis. Toxicol Lett 102-103:139-142.

Novgorodov SA, Gudz TI, Milgrom YM, Brierly GP (1992) The permeability transition in heart mitochondria is regulated synergistically by ADP and cyclosporin A. J Biol Chem 267:16274-16282.

Nowicki JP, Assumel-Lurdin C, Duverger D, MacKenzie ET (1988) Temporal evolution of regional energy metabolism following focal cerebral ischemia in the rat. J Cereb Blood Flow Metab 8:462-473.

Panov AV, Gutekunst CA, Levitt BR, Hayden MR, Burke JR, Strittmatter WJ, Greenamyre JT (2002) Early mitochondrial calcium defects in Huntington's disease are a direct effect of polyglutamines. Nat Neurosci 5:731-736.

Petersen A, Larsen KE, Behr GG, Romero N, Przedborski S, Brundin P, Sulzer D (2001) Expanded CAG repeats in exon 1 of the Huntington's disease gene stimulate dopamine-mediated striatal neuron autophagy and degeneration. Hum Mol Genet 10:1243-1254.

Pettus EH, Betarbet R, Cottrell B, Wallace DC, Madyastha, Greenamyre JT (2000) Immunocytochemical characterization of the mitochondrially encoded ND1 subunit of complex I (NADH: ubiquinone oxidoreductase) in rat brain. J Neurochem 75:383-392.

Pulsinelli WA, Duffy TE (1983) Regional energy balance in rat brain after transient forebrain ischemia. J Neurochem 40:1500-1503.

Ryder E (1980) Enzymatic profile of mitochondria isolated from selected brain regions of young adult and one-year-old rats. J Neurochem 34:1550-1552.

Sawa A, Wiegand GW, Cooper J, Margolis RL, Sharp AH, Lawler Jr JF, Greenamyre JT, Snyder SH, Ross CA (1999) Increased apoptosis of Huntington disease lymphoblasts associated with repeat lengthdependent mitochondrial depolarization. Nat Med 5:1194-1198.
Schilling G, Coonfield ML, Ross CA, Borchelt DR (2001) Coenzyme Q10 and remacemide hydrochloride ameliorate motor deficits in a Huntington's disease transgenic mouse model. Neurosci Lett 315:149-153.

Sims NR (1990) Rapid isolation of metabolically active mitochondria from rat brain and subregions using Percoll density gradient centrifugation. J Neurochem 55:698-707.

Sokoloff L, Reivich M, Kennedy C, Des RM, Patlak CS, Pettigrew KD, Sakurada O, Shinohara M (1977) The $\left[{ }^{14} \mathrm{C}\right]$ deoxyglucose method for the measurement of local cerebral glucose utilization: theory, procedure, and normal values in the conscious and anesthetized albino rat. J Neurochem 28:897-916.

Sonnewald U, Hertz L, Schousboe A (1998) Mitochondrial heterogeneity in the brain at the cellular level. J Cereb Blood Flow Metab 18:231-237.

Sybirska E, Davachi L, Goldman-Rakic PS (2000) Prominence of direct entorhinal-CA1 pathway activation in sensorimotor and cognitive tasks revealed by $2-D G$ functional mapping in nonhuman primate. J Neurosci 20:5827-5834.

Szabo I, Zoratti M (1989) The inner mitochondrial membrane contains ion-conducting channels similar to those found in bacteria. FEBS Lett 259:137-143.

Szabo I, Zoratti M (1991) The giant channel of the inner mitochondrial membrane is inhibited by cyclosporin A. J Biol Chem 266:3376-3379.

Turrens JF, Alexandre A, Lehninger AL (1985) Ubisemiquinone is the electron donor for superoxide formation by complex III of heart mitochondria. Arch Biochem Biophys 237:408-414.

Vertechy M, Cooper MB, Ghirardi O, Ramacci MT (1993) The effect of age on the activity of enzymes of peroxide metabolism in rat brain. Exp Gerontol 28:77-85.

Vignais PV, Brandolin G, Boulay F, Dalbon P, Block M, Gauche I (1989) Anion carriers of mitochondrial membranes (Azzi A, Fonyo A, Nalecz MJ, Vignais PV, Wojtczak L, eds), pp 133-146. Berlin: Springer.

Votyakova TV, Reynolds IJ (2001) $\Delta \psi_{\mathrm{m}}$-Dependent and -independent production of reactive oxygen species by rat brain mitochondria. J Neurochem 79:266-277.

Wanker EE (2000) Protein aggregation and pathogenesis of Huntington's disease: mechanisms and correlations. Biol Chem 381:937-942.

Woodfield K, Ruck A, Brdiczka D, Halestrap AP (1998) Direct demonstration of a specific interaction between cyclophilin-D and the adenine nucleotide translocase confirms their role in the mitochondrial permeability transition. Biochem J 336:287-290.

Yamada K, Uozumi T, Kawasaki T, Sogabe T, Ohta K (1988) Regional changes in the cellular level of adenine nucleotides in ischemic rat brain subjected to single embolization. J Neurochem 51:141-144.

Zaidan E, Sims NR (1997) Reduced activity of the pyruvate dehydrogenase complex but not cytochrome $c$ oxidase is associated with neuronal loss in the striatum following short-term forebrain ischemia. Brain Res 772:23-28.

Zoratti M, Szabo I (1995) The mitochondrial permeability transition. Biochim Biophys Acta 1241:139-176. 